\title{
Librarians and University Presses of the World Unite!: Efforts to Resuscitate the Knowledge Commons of Academic Publishing
}

\section{Wilhelm Peekhaus}

School of Information Studies, University of Wisconsin-Milwaukee, Northwest Quadrant Bldg. B, 2025 E Newport, Milwaukee, Wisconsin, USA, 53211. E-Mail: peekhaus@uwm.edu; Tel.: +1-414229-5033; Fax: +1-414-229-6699

\section{Introduction}

As is relatively well known, Henry Oldenburg, the first Joint Secretary of the then newly founded Royal Society of London, published in 1665 the world's first scholarly journal, Philosophical Transactions. Oldenburg established the journal to fulfill four functions that continue today as part of the scholarly communication process: registration, which ensures the article is connected to the author as well as the intellectual property right holder; certification of the quality of the research through peer review; dissemination of the research; and archiving to ensure historical preservation and future availability of research. The scholarly publishing system remained confined largely to learned societies for roughly the following three centuries, until commercial publishers began to recognize and exploit the profit potential of academic literature. Sustained annual growth in the number of journals and articles, accompanied by aggressive merger and acquisition activity among the major publishing conglomerates, has resulted in a contemporary multi-billion dollar industry dominated by a handful of publishing behemoths that extract immense resources from institutions of higher education based on the free labour of academics.

And while the largest of the commercial publishers that now dominate the academic publishing ecosystem declare that they are vital to ensuring the effective discharge of the key aspects of the scholarly communication system, the proposed paper will suggest that their command and extreme rent-seeking behavior is parasitic on scholarly communication and ultimately stymies the system. Moreover, and this is the more novel element of the argument to be developed, this stranglehold is superfluous and could be loosened in a way that would restore substantial control over the academic journal publishing system to stakeholders and institutions more closely aligned with the interests of the actual producers and users of scholarly works. Considered in broad brush strokes, the paper will argue that contemporary information and communication techologies, in tandem with open source digital publishing management platforms, have made it technologically, logistically, and financially feasible 
for scholarly journal publishing to be reclaimed by members of the academy through their non-profit university presses and libraries in ways that would respond to the serials crisis experienced by academic libraries while ensuring fidelity to the traditional processes of the scholarly communication system.

\section{A General Overview of the Western Academic Publishing Industry}

According to the most recent data collected by the consulting firm Outsell, revenues in 2011 for the science-publishing industry amounted to US\$9.4 billion. Based on 1.8 million English-language articles published annually by 3,500 publishers in 27,000 journals, this figure translates into gross revenue of slightly more than US\$5,200 per article [as cited in 1]. ${ }^{\mathrm{i}}$ The academic publishing industry is now dominated by ten major corporations. The top three publishers of scientific journals (Elsevier, Springer, and Wiley-Blackwell) account for approximately 42 percent of all articles published. In part, this concentrated degree of control has been made possible because these large commercial publishers have been very successful in acquiring many of the most prestigious and high-circulation journals across almost all academic disciplines.

In an attempt to justify the high rents they extract when selling access to the knowledge created by academic labourers, publishers typically invoke claims about adding value to the broader knowledge ecology. Such assertions completely sidestep the reality that unpaid academic labour provides the content, peer-review, and editorial work (although a few publishers pay editors a small stipend, it is typically well below the true value of the person's efforts) being appropriated by journal publishers. These types of claims also occlude the additional time and money burdens typically downloaded onto authors should their manuscript contain colour material, or require copyright release for images and other copyrighted material they might want to incorporate into their work. And even this value-added work is appropriated by publishers who coerce authors into surrendering their intellectual property rights as a precondition for publication.

\section{Open Access Responses}

In response to several of the trends in the academic publishing industry that have clearly disadvantaged both authors and libraries - that is, the producers and the purchasers of scholarly output - a sustained movement has emerged over the last decade and a half that advocates for and develops open-access models to academic research. The two dominant accepted models for delivering open access to scholarly works are known as 'Gold' and 'Green' open access. Gold open access refers to peer-reviewed publication in an open-access journal, whereas Green open access involves deposit of the work in an institutional or subject electronic repository. Beyond the mounting success of the Green model that relies on repositories, recent research provides additional evidence that open-access journal publishing has matured into a sustainable form of scholarly publication [2]. As might also be expected given such monumental growth, open-access infrastructure and technical applications have advanced considerably. In particular, Open Journal Systems, a journal management and publishing system developed by the Public Knowledge Project, has become a widely used software platform by over 5,800 open-access journals.

Unfortunately, the corporate publishing oligarchs have also recognized the capital accumulation opportunities offered by open-access models. All of the leading corporate academic publishers now 
offer Green and Gold open-access options at a range of different, and exorbitant, price points (e.g., depending on the publisher and the journal, Green open-access options can be purchased for US\$1,500 and Gold open access tends to run between US\$2,000 and US\$3,000). The fact that there is such a range of article processing charges indicates that they are less a reflection of actual production costs and instead based more on a calculus of what the market will bear. Clearly, open access per se will not necessarily improve the long-term financial sustainability of the scholarly communication system. Instead, these corporate adaptations to open access represent a direct response by commercial publishers to subvert the open-access model in service of their own accumulation imperatives. Indeed, according to analysts at Bernstein Research, which upgraded its stock outlook for Reed Elsevier in September 2014 to market-perform from underperform in 2011, open access has done little to challenge the market strength of the leading subscription publishers. Instead, these analysts suggest that open-access funding models may actually be contributing to the profits of scientific, technical, and medical (STM) journal publishers. This assessment has certainly been borne out in the case of Elsevier, which has been steadily increasing its operating profit margins over the last few years for its STM journals: 36 percent ( $£ 724$ million) in 2010, 37 percent ( $£ 768$ million) in 2011, 38 percent ( $£ 780$ million) in 2012, and 39 percent (£826 million) in 2013. These same analysts predict further consolidation of the industry, which would favour the larger players such as Elsevier [3].

\section{Toward a More Substantive Transformation of the Scholarly Publishing System}

All academics, but especially tenured faculty, need to be reminded of their role in the broader knowledge ecology and the constraining effects that the current commercial model of journal publishing exercises on this ecology. At the risk of stating the obvious, this is critical since academics benefit from their work being widely disseminated and used (and hopefully cited), not from royalty streams. Put more directly, there is a disconnect between the factors motivating the typical academic writer and the profit maximising behaviour of commercial publishers. Academics provide the majority of labour that sustains the production of scholarly knowledge, including the actual research and writing, peer review, and editing. It is time for academics to re-appropriate from for-profit publishers the products and processes of our collective labour in order to revitalise the knowledge commons in ways that serve the public good rather than commercial accumulation imperatives. And although this might require significant amounts of persuasion among some of our more conservative colleagues, I suggest that logistically such a re-appropriation would be less difficult.

There already exists a basic publishing infrastructure in the form of non-profit university presses, which should be able to substitute easily for commercial publishers in ways that would not require the assignment of copyright by authors or the imposition of onerous pricing and licensing contracts on library customers. Indeed, university presses have substantial historical experience in facilitating the dissemination of scholarly research across multiple product lines (trade books, scholarly monographs, textbooks, and journals). And, as pointed out above, there exist freely available, technologically sophisticated digital publishing platforms (e.g., Open Journal Systems) of which university presses could avail themselves. I therefore believe that university presses are best positioned to fulfill the key aspects of the scholarly communication system in ways that would promote access while also remedying the fiscal instability of the current corporate-dominated model. 
Moreover, and this is the part of the paper that will be further elaborated for the conference, university presses can partner with the increasing number of university libraries that have coalesced through the Library Publishing Coalition project. This group of 60 North American academic libraries has committed itself to expanding the nascent field of library publishing in collaboration with university presses and learned societies. The findings reported in this part of the paper will outline some of the lessons and best practices learned so far by this group of librarians who are actively seeking to collaboratively transform academic publishing into a commonist endeavour better aligned with the production processes and consumption practices of the actual producers and consumers of academic research.

\section{Conclusions}

Commercial control of academic publishing through strategies and practices such as industry consolidation and forced assignment of copyright represents an appropriation and enclosure of the knowledge commons that otherwise would emerge from the unrestricted flow of academic research. Put another way, commercial control of academic publishing expedites the private expropriation of much of the value that is produced in common through the cooperative relationships inherent in scholarly production. Yet such appropriation and enclosure need not be tolerated. The success of the open-access movement and models has demonstrated that there are viable alternatives to the commercial control of academic publishing. However, the dominant open-access regime suffers from inherent neutrality in respect of economic model that renders it susceptible to commercial appropriation and exploitation. The author-pay model does nothing to destruct the commodity logic of academic publishing but instead merely transfers the revenue source from users/readers to the actual producers (authors), which introduces yet another level of exploitation of the producers. Thus, while sympathetic to the goals and objectives of (Gold) open access, I assert that the more formidable imbalance in the scholarly publishing system is the presence and substantial control exercised by forprofit publishers. I therefore believe that we need to become more radical in our thinking and our actions in order to wrest control of academic publishing from the current commercial publishing oligarchs. A group of academic librarians, through their institutions, has begun to try and actively reappropriate such control. The review and assessment of selected examples of collaborative publishing projects being undertaken by some university presses and academic libraries shines an optimistic light on efforts to exert autonomous self-control over our knowledge commons.

\section{References and Notes}

1. Van Noorden R. The true cost of science publishing: Cheap open-access journals raise questions about the value publishers add for their money. Nature 2013; 495: 426-9.

2. Laakso M, Welling P, Bukvova H, Nyman L, Björk B-C, Hedlund T. The development of open access journal publishing from 1993 to 2009. PLOS ONE [serial on the Internet]. 2011; 6(6): Available from: http://dx.doi.org/10.1371\%2Fjournal.pone.0020961.

3. Aspesi C, Luong H. Reed Elsevier: Goodbye to Berlin - The fading threat of open access (upgrade to market-perform). New York: Sanford C. Bernstein \& Co., LLC, 2014. 
${ }^{\mathrm{i}}$ Information about the current make-up of the academic publishing industry, including aggregate revenue figures, is surprisingly difficult to locate. Most authors tend to draw on data collected by two private consulting firms, Outsell and Simba Information. However, the price tag of the report compiled by Outsell is $\$ 1,850$. The price of Simba's report, $\$ 3,250$, is even more prohibitive. Multiple efforts by the author to secure a copy of either report through interlibrary loan failed.

(C) 2015 by the authors; licensee MDPI and ISIS. This abstract is distributed under the terms and conditions of the Creative Commons Attribution license. 